\title{
PEB Regimen
}

National Cancer Institute

\section{Source}

National Cancer Institute. PEB Regimen. NCI Thesaurus. Code C128248.

A chemotherapy regimen consisting of bleomycin, etoposide and cisplatin used for the treatment of pediatric germ cell tumors (GCT). In the PEB regimen, the pediatric patients receive bleomycin once per cycle and do not receive weekly bleomycin during the weeks between cycles (every 21 days); in the adult BEP regimen, patients receive weekly bleomycin. 